Note

\title{
Effects of Dipping Solutions on Air-Drying Rates of the Seedless Grapes
}

\author{
Osman IsmaIL ${ }^{*}$, Seyfullah Keyf, Berceste BeyriBey and Burcu ÇORBACIOĞLU
}

Ylldı Technical University, Davutpasa Campus, Faculty of Chemical-Metallurgical, Department of Chemical Engineering, 34210

Esenler, Istanbul, Turkey

Received November 9, 2007; Accepted July 3, 2008

Preserving of food by drying, has been became an important subject in food industry. Turkey has a high potential at fruit production. Grape has an economically important role in Turkey's export. The effects of different dipping solutions on hot air drying of grapes were studied. The Sultana grape was used In drying experiments. Seedless grapes treated with oleic acid and potassium carbonate solutions or untreated were dried by air at $50^{\circ} \mathrm{C}, 60^{\circ} \mathrm{C}$ and $70^{\circ} \mathrm{C}$. Pretreated grapes dried faster than naturally dried. According to colour results, red colour on grapes pretreated with oleic acid solutions was preserved beter than naturally dried.

Drying rates of grapes were modelled by the Page and Exponential equations. The model results agreed with experimental results.

Keywords: Seedless grapes, pretreatment solution, drying, oleic acid

\section{Introduction}

Turkey which is an agriculture country has a fruit and vegetable production capacity due to whether ecological conditions and geographical location. In order to keep and prevent going bad, drying and cold storing techniques of fresh fruits and vegetable which are possessed of high percent moisture are important.

Drying is described as decreasing of existing moisture by hot air to storable level in order to decrease biological, chemical and microbiological spoil (Doymaz and Pala, 2003). Beside decreasing in volume and weight achievement by drying, it has some advantages as storing, smaller packing and lower transport cost (Mujumdar, 1995). The well known drying technique in Turkey and on the world is openair drying. Drying at open-air has lost its importance because this technique is slow and causes microbial and bacterial contamination, left foreign materials by animals. Nowadays solar and hot-air drying processes which present long shelf life and hygenic products and time saving are popular processes that alternate to conventional open-air process (Akpinar et al., 2003; Maskan, 2001). Drying of seed free grape which is an important market not only in Turkey but also on

*To whom correspondence should be addressed.

Email: ismail@yildiz.edu.tr the World, will be described in this study. Turkey was at the sixth sequence in dried seed free grape production in the year 2003. Those dried grapes known as Sultana and Thompson are grown at Aegean Region in Turkey.

Drying techniques were drawn attention of many researchers and many studies were done on the world (Hutchinson and Otten, 1983; Kitic and Viollaz, 1984). The most important point to pay attention is to remove wax film on grape that resists mass transfer during drying. For this purpose fatty acid esters (methyl, ethyl or oleate and oleic, stearic and caprillic acid) and some chemicals (caustic and sulfur) are widely used for pre- processing of grape drying. The researchers have proved that pre-processed grape using dipping solutions, drying increases and so drying time decreases four times according to non pre-processed grapes (Bolin et al., 1975; Di Matteo et al., 2000; Kostaropoulos and Saravacos, 1995; Saravacos and Marousis, 1988).

The aim of this study is to investigate the rate of drying in a hot air drier and the color of the final product. Also drying time and color quality of dried untreated seed free grape will be compared with pretreated by dipping solutions. Page and Exponential Models for describing the drying process were investigated and effective diffusivity of seedless grape was also calculated. 


\section{Mathematical Modelling}

It has been accepted that drying phenomenon of biological products during the falling rate period is controlled by the mechanism of liquid and vapour diffusion. The first takes into account only internal resistance to moisture transfer while the other two consider only external resistance to moisture transfer resistance between product and air (Fortes and Okos, 1981; Henderson, 1974; Panchariya et al., 2002). The theoretical model employed in this study is based on Fick's law of diffusion using spherical coordinates. The solution to Fick's equation, with the assumptions of moisture migration being by diffusion, negligible volume shrinkage, constant, temperature and diffusion coefficients (Crank, 1975; Di Matteo et al., 2000; Tolaba and Suarez, 1988; Tütüncü and Labuza, 1996) is:

$$
M R=\frac{M-M_{e}}{M_{0}-M_{e}}=\frac{6}{\pi^{2}} \sum_{n=1}^{\infty} \frac{1}{n^{2}} \exp \left(-\frac{n^{2} \pi^{2} D_{e f f}}{R^{2}} t\right)
$$

By considering just the first term of the above series, it is possible to describe the logaritmic reduction of the first term of Eq.(1) as a linear function of time, as previously proposed by (Peri and Riva, 1984).

$$
\ln \left(\frac{M-M_{e}}{M_{0}-M_{e}}\right)=\ln \left(\frac{6}{\pi^{2}}\right)-\left(\frac{\pi^{2} D_{e f f}}{R^{2}}\right) t
$$

Eq.(2) can also be written in a more simplified form as:

$$
\frac{M-M_{e}}{M_{0}-M_{e}}=k \exp (-c t)
$$

The Page model, developed by (Page, 1949) is an empirical modification of the simple exponential model to correct for the short comings mentioned previously. It is written in the form of

$$
\frac{M-M_{e}}{M_{0}-M_{e}}=\exp \left(-x t^{y}\right)
$$

The effective moisture diffusivity was calculated using the method of slopes.Diffusion coefficients $\left(D_{\text {eff }}\right)$ are typically determined by plotting experimental drying data in terms of $\ln \left[\left(\mathrm{M}-\mathrm{M}_{\mathrm{e}}\right) /\left(\mathrm{M}_{\mathrm{o}}-\mathrm{M}_{\mathrm{e}}\right)\right]$ versus time, as given by Eq.(2) was used (Lomauro et al., 1985; Tütüncü and Labuza, 1996).

From Eq. (2), a plot of $\ln \left[\left(\mathrm{M}_{\mathrm{e}} \mathrm{M}_{\mathrm{e}}\right) /\left(\mathrm{M}_{\mathrm{o}}-\mathrm{M}_{\mathrm{e}}\right)\right]$ versus time gives a straight line with a slope $\left(\mathrm{k}_{\mathrm{o}}\right)$ of:

$$
\text { slope }=\frac{\pi^{2} D_{\text {eff }}}{R^{2}}
$$

\section{Materials and Processes}

Materials The uniform size of grape (average length 1.9 - 2.3) originated by Manisa (Vitis vinifera L.) was used in all experiments. The average initial moisture content of the grapes was $79.5 \%$, in wet basis. The moisture content of fresh and dried grape was obtained according to the AOAC method (1990). Air flow rate and colour parameters were measured by an anemometer (LUTRON, AM-4201, Taiwan) and a Hunter Lab Colour D 25 instrument (Hunter Ass. Laboratory, Virginia, USA) respectively. The drying process was carried out in a laboratory type cabinet dryer manifactured by MAKİMSAN (Turkey). The dryer includes a blower, a air fitler, an electric heater and a drying tray.

The dipping and drying process $1 \mathrm{~kg}$ of fresh grape was used for each experiment. Technical grade and merck chemicals were used for dipping solutions. Grape was dipped in several solutions and dried afterward. Pretreatment (dipping) solutions were given below.

D1: 2\% oleic acid (Merck, Germany) solution, dipping at ambient temperature for 2 minutes

D2: 5\% Potassium carbonate (TEKKİM, Turkey) solution, dipping at ambient temperature for 2 minutes

The drying process was carried out at air velocity and temperatures $1.5 \mathrm{~m} / \mathrm{s}$ and of $50,60,70^{\circ} \mathrm{C}$ respectively.

D3 : Untreated grape was dried naturally at 50, 60 and $70^{\circ} \mathrm{C}$ air respectively.

\section{Results and Discussion}

Drying operation and determination of dry characteristics of grapes Drying curves are shown in Fig. 1. The drying times of grape samples which were dipped in oleic acid and potassium carbonate solutions and natural were 1350, 1380 and 3090 minutes respectively at $60^{\circ} \mathrm{C}$. These results demonsrated that drying time of grape samples treated with oleic acid solution was decreased by $2.2 \%$ according to samples treated with potassium carbonate and $128.8 \%$ according to untreated samples. It was observed that the temperature has also an important effect in drying operation like preliminary operations.

Colour Analysis Colour analysis for dried products were carried out in an Hunter Lab Color D 25. The measurements were repeated for four different point and an average of those values is taken. The evaluation of colour analysis of dried product were carried out using the average value of $\mathrm{L},+\mathrm{a}$ and $+\mathrm{b}$ according to Hunter colorymetric system. " $\mathrm{L}$ ", " $+\mathrm{a}$ " and " $+b$ " values show that the colour is going to lightness, redness and yellowness, respectively.. The results of colour analysis are given in Table 1. As it can be seen in Table 1, dipping solutions have an important effect on quality parameters of dried grape. When the "L" and "a/b" proportions of grape dried after dipping into the oleic acid were examined, it is observed that the colour quality is better. For example, the values of $\mathrm{L}$ and $\mathrm{a} / \mathrm{b}$ were 22.68 - 0.78 oleic acid, 21.55 - 0.83 potassium carbonate, 19.32 - 0.84 natural for grapes 


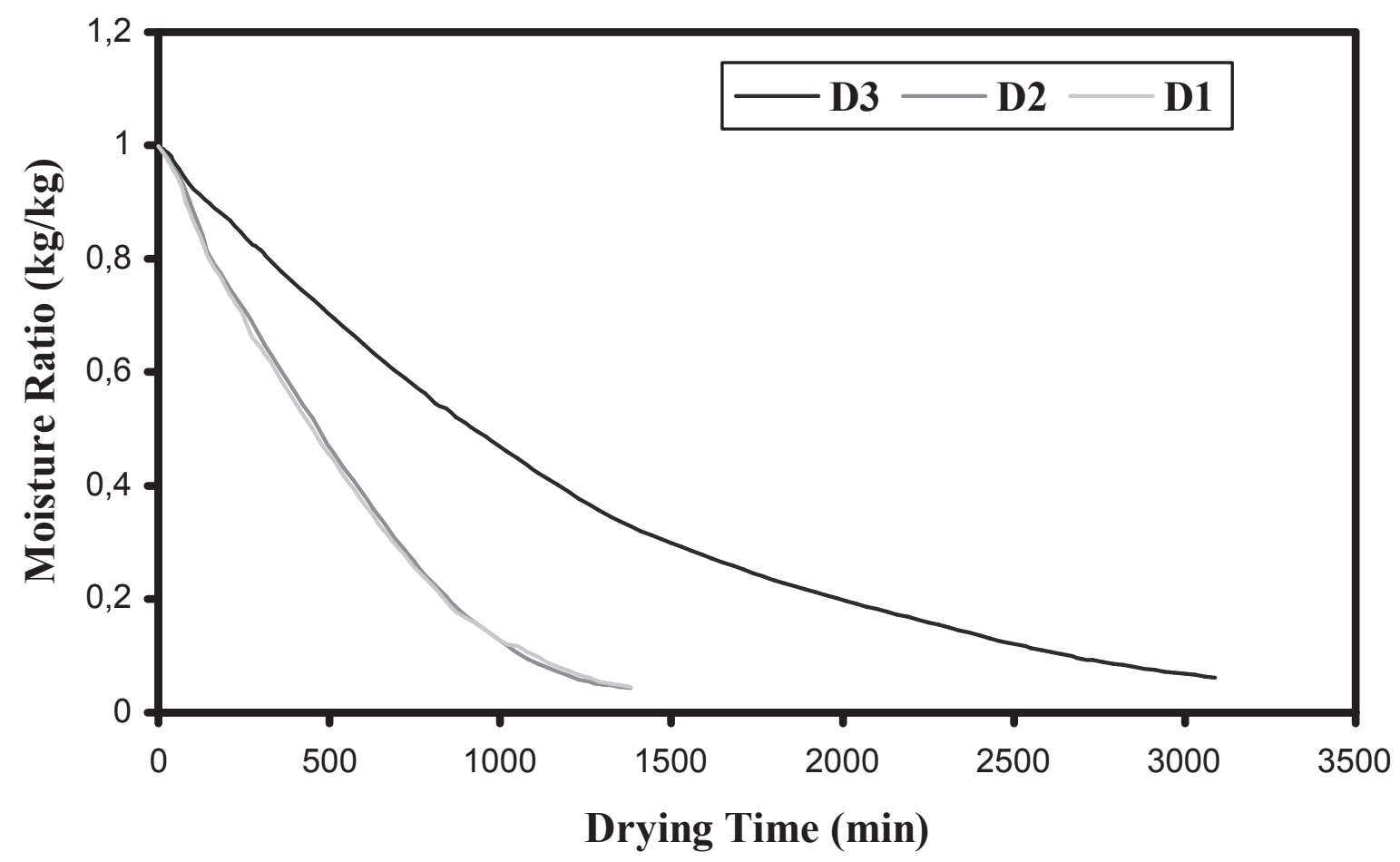

Fig. 1. The drying curves of grapes dried at $60^{\circ} \mathrm{C}$ after different pretreatments.

Table 1. Drying times and colour analysis of dried grapes.

\begin{tabular}{|c|c|c|c|c|c|c|}
\hline Code & $\begin{array}{c}\text { Air } \\
\text { temperature } \\
\left({ }^{\circ} \mathrm{C}\right)\end{array}$ & $\begin{array}{c}\text { Drying } \\
\text { time (min) }\end{array}$ & $\mathbf{L}$ & $+\mathbf{a}$ & $+\mathbf{b}$ & $\mathbf{a} / \mathbf{b}$ \\
\hline D1 & 50 & 2220 & 18.75 & 2.84 & 3.58 & 0.79 \\
\hline \multirow[t]{2}{*}{$2 \%$ oleic acid } & 60 & 1350 & 20.96 & 4.89 & 6.11 & 0.80 \\
\hline & 70 & 900 & 22.68 & 5.12 & 6.49 & 0.78 \\
\hline $\mathrm{D} 2$ & 50 & 2400 & 18.59 & 3.48 & 3.96 & 0.87 \\
\hline (Potassium carbonate) & 60 & 1380 & 20.03 & 4.57 & 5.59 & 0.81 \\
\hline $5 \% \mathrm{~K}_{2} \mathrm{CO}_{3}$ & 70 & 1020 & 21.55 & 4.47 & 5.34 & 0.83 \\
\hline D3 & 50 & 4050 & 17.59 & 3.86 & 4.31 & 0.89 \\
\hline \multirow[t]{2}{*}{ NATURAL } & 60 & 3090 & 18.92 & 3.07 & 3.53 & 0.86 \\
\hline & 70 & 1200 & 19.32 & 4.01 & 4.73 & 0.84 \\
\hline
\end{tabular}




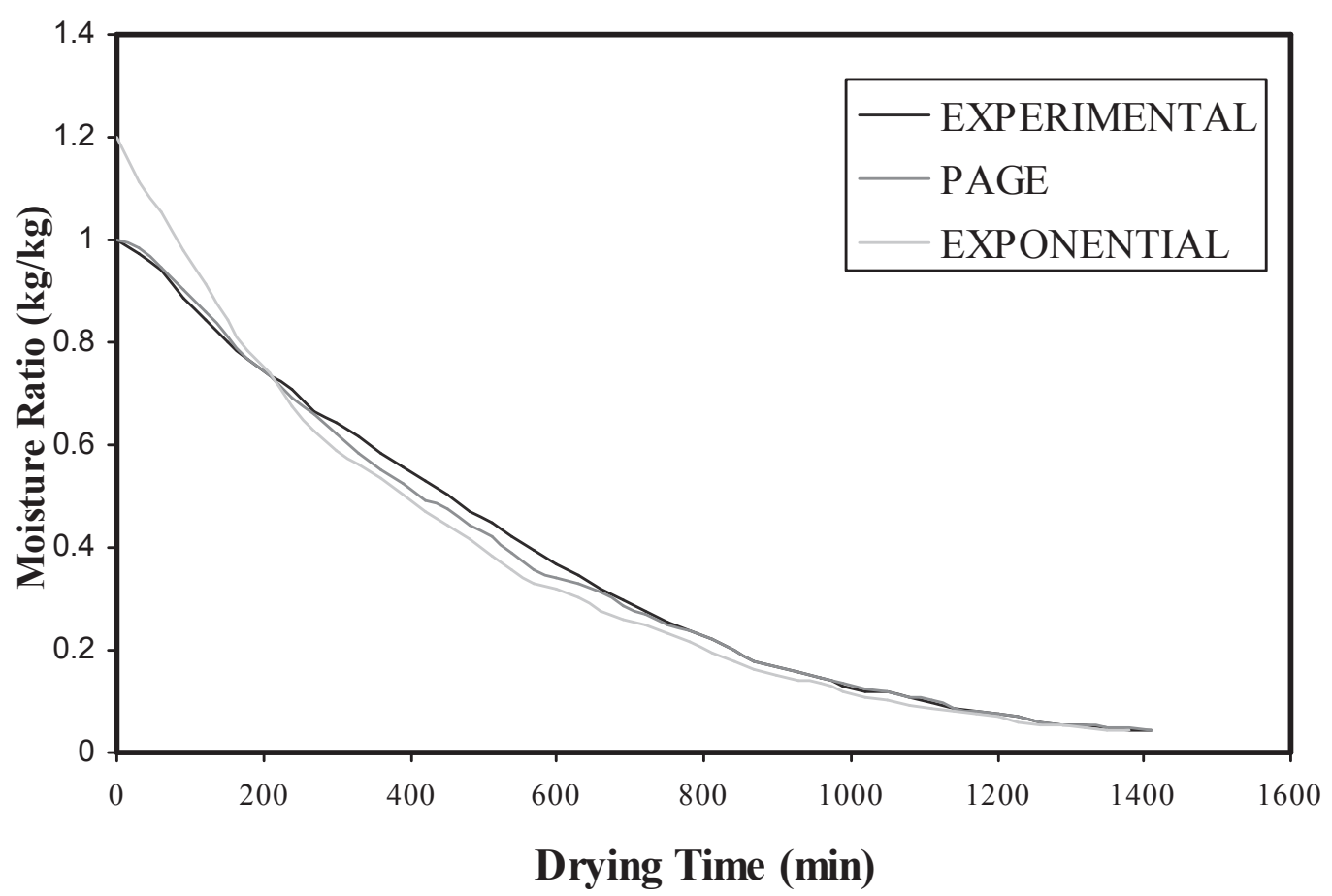

Fig. 2. The experimental and fitted drying curves for grapes dipped in oleic acid solution at $60^{\circ} \mathrm{C}$.

Table 2. The correlation and diffusion coefficients.

\begin{tabular}{ccccc}
\hline Code & Air temperature $\left({ }^{\circ} \mathbf{C}\right)$ & $\mathbf{r}^{2}($ Page $)$ & $\mathbf{r}^{2}(\mathbf{E x p})$ & $\mathbf{D}_{\text {eff }}\left(\mathbf{m}^{2} \mathbf{s}^{-1}\right)$ \\
\hline D1 & 50 & 0.997 & 0.979 & $8.56 \times 10^{-10}$ \\
$2 \%$ oleic acid & 60 & 0.997 & 0.985 & $1.99 \times 10^{-9}$ \\
& 70 & 0.998 & 0,995 & $3.57 \times 10^{-9}$ \\
D2 & 50 & 0.995 & 0.976 & $8.36 \times 10^{-10}$ \\
(Potassium carbonate) & 60 & 0.997 & 0.992 & $1.94 \times 10^{-9}$ \\
$5 \% \mathrm{~K}_{2} \mathrm{CO}_{3}$ & 70 & 0.996 & 0.991 & $2.45 \times 10^{-9}$ \\
D3 & 50 & 0.995 & 0.978 & $7.91 \times 10^{-10}$ \\
NATURAL & 60 & 0.997 & 0.987 & $9.27 \times 10^{-10}$ \\
& 70 & 0.996 & 0.994 & $1.94 \times 10^{-9}$ \\
\hline
\end{tabular}


dried at $70^{\circ} \mathrm{C}$, respectively. High " $\mathrm{L}$ " and low "a/b" values are demanded. The temperature increase loads to an increase in "L" values of dried grapes as it is shown in Table 1.

Calculation of correlation and diffusion coefficients The correlation coefficients $\left(\mathrm{r}^{2}\right)$ calculated applying the theoritical Page and Exponential equations are given in Table 2.

Exponential model : $\frac{M}{M_{0}}=k \exp (-c t)$

Page model : $\quad \frac{M}{M_{0}}=\exp \left(-x t^{y}\right)$

One can observe from Table 2 that the $\mathrm{r}^{2}$ values calculated using Page equations are higher than the values calculated using Exponential equations. As it can be seen in the figures above, the results of the experiments and the results obtained using theoritical models are consistent with each other.

The variation of moisture content of products with drying time calculated experimentally and using Page and Exponential equations for the products dried at $60^{\circ} \mathrm{C}$ are given in Fig. 2 .

Drying curves of the grapes which obtained from the data are plotted using the Page and Exponential equations. $r^{2}$ of Page equation is higher than $r^{2}$ of exponential equation. The diffusion coefficients of grapes dried at $70^{\circ} \mathrm{C}$ were $3.57 \times$ $10-9 \mathrm{~m} 2 / \mathrm{s}, 2.45 \times 10^{-9} \mathrm{~m}^{2} / \mathrm{s}, 1.94 \times 10^{-9} \mathrm{~m}^{2} / \mathrm{s}$, respectively. These values of $D_{\text {eff }}$ shows that the drying rate increases due to oleic acid solution.

\section{Conclusion}

It is observed that grape samples which were pretreated with oleic acid and potassium carbonate solutions, dried faster than the untreated samples. The oleic acid dipping has increased the drying rates according to the potassium carbonate pretreatment and appearance of the dried grapes. Oleic acid has destroyed the resistance of waxy layer which prevents moisture transfer and increased the drying rate.

Color analysis showed that colour of grape samples pretreated with oleic acid and potassium carbonate $(\mathrm{L}$ and $\mathrm{a} / \mathrm{b}$ values) were better than untreated samples. The best results were obtained with grape dried after dipping in oleic acid solutions. It was investigated that temperature has an important effect in colour parameters.

The $r^{2}$ values calculated using Page equations were higher than the values calculated using Exponential equations but they were consistent with each other. The diffusion coefficients of grape samples dipped in oleic acid were higher than samplestreated by potassium carbonate solution and naturally (untreated).

It was concluded that the best results for all experiment were obtained with grape dried after dipping in oleic acid solutions.

\section{Nomenclature}

$\begin{array}{ll}\mathrm{MR} & \text { moisture ratio }=\left(\mathrm{M}-\mathrm{M}_{\mathrm{e}}\right) /\left(\mathrm{M}_{\mathrm{o}}-\mathrm{M}_{\mathrm{e}}\right) \\ \mathrm{M} & \text { moisture content at time } t, \mathrm{~kg} \text { moisture/kg dry matter } \\ \mathrm{M}_{\mathrm{e}} & \text { equilibrium moisture content, kg moisture/kg dry matter } \\ \mathrm{M}_{\mathrm{o}} & \text { initial moisture content, } \mathrm{kg} \text { moisture } / \mathrm{kg} \text { dry matter } \\ \mathrm{D}_{\text {eff }} & \text { diffusion coefficient }\left(\mathrm{m}^{2} / \mathrm{s}\right) \\ \mathrm{r}^{2} & \text { correlation coefficient } \\ \mathrm{x} & \text { drying constant } \\ \mathrm{c} & \text { drying constant } \\ \mathrm{y} & \text { drying constant } \\ \mathrm{k} & \text { drying constant } \\ \mathrm{t} & \text { time (s) } \\ \text { D1 } & \text { oleic acid } \\ \text { D2 } & \text { potassium carbonate } \\ \text { D3 } & \text { natural (untreated) } \\ \mathrm{L} & \text { lightness } \\ \text { a } & \text { redness } \\ \text { b } & \text { yellowness }\end{array}$

\section{References}

AOAC.(1990). Official methods of analysis. In Heldrich,K. (Ed.), “Association of official analytical chemists (15th ed.)." Washington, USA, p. 1298.

Akpinar, K.E., Bicer,Y. and Yildiz,C. (2003). Thin layer drying of red pepper. J. Food Eng., 59, 99-104.

Bolin, H.R., Petrucci,V. and Fuller,G. (1975). Characteristics of mechanically harvested raisins produced by dehydration and by field drying. J. Food Sci., 40, 1036-1038.

Crank, J. (1975). "The mathematics of diffusion. (second ed.)." Clarendon Press, Oxford, UK.

Di Matteo, M., Cinquanta, L. Galiero, G. and Crescitelli, S. (2000). Effect of a novel physical pretreatment process on the drying kinetics of seedless grapes. J. Food Eng., 46, 83-89.

Doymaz, İ. and Pala, M. (2002). The Effects of Dipping Pretreatments on Air-Drying Rates of the Seedless Grapes. J. Food Eng., 52, 413-417.

Doymaz, İ. and Pala, M. (2003). The thin-layer drying characteristics of corn. J. Food Eng., 60, 125-130.

Fortes, M. and Okos, M.R. (1981). Non-equilibrium thermodynamics approach to heat and mass transfer in corn kernels. Trans. ASAE, 22, 761-769.

Henderson, S.M. (1974). Progress in developing the thin layer drying equation. Trans. ASAE, 17, 1167-1172.

Hutchinson, D. and Otten, L. (1983). Thin layer air drying of soybeans and white beans. J. Food Technol., 18, 507-524.

Kitic, D. and Viollaz, P. E. (1984). Comparison of drying kinetic of soybeans in thin layer and fluidized beds. J. Food Technol., 19, 399-408.

Kostaropoulos, A.E. and Saravacos, G.D. (1995). Microwave PreTreatment for Sun-Dried Raisins. J. Food Sci., 60, 344-347. 
Lomauro, C.J., Bakshi, A.S. and Labuza, T.P. (1985). Moisture transfer properties of dry and semimoist foods. J. Food Sci., 50, 397-400.

Maskan, M. (2001). Drying, shrinkage and rehydration characteristic of kiwifruits during hot air and microwave drying. J. Food Eng., 48, 177-182.

Mujumdar, A.S. (1995). "Handbook of Industrial Drying.” Marcel Dekker, New York.

Page, G.E. (1949). Factors influencing the maximum rates of air drying shelled corn in thin layer. Masters thesis Purdue University. Lafayette, IN (unpublished).

Panchariya, P.C., Popovic, D. and Sharma, A. L. (2002). ThinLayer Modelling of Black Tea Drying Process. J. Food Eng., 52,
349-357.

Peri, C. and Riva, M. (1984). Etude du sechage des raisins 2: Effet des traitments de modification de la surface sur la qualite du produit. Sci. Aliment., 4, 273-286.

Saravacos, G D. and Marousis, S.N. (1988). Effect of Ethyl Oleate on the Rate of Air-Drying of Foods. J. Food Sci., 7, 263-270.

Tolaba, M.P. and Suarez, C. (1988). Simulation of thin-layer drying of corn by means of the diffusional model. Lebens. Wiss. U.-Technol., 21, 83-86.

Tütüncü, A.M. and Labuza, T. P. (1996). Effect of geometry on the effective moisture transfer diffusion coefficient. J. Food Eng., 30, 433-447. 